\title{
Expression of VWF and Interferon $\gamma$ in renal allograft biopsies and correlation with inflammatory cells. Single center experience.
}

\author{
Alaa Abbas Ali*, Kais H Al-Taee², Zana Sidiq M Saleem²
}

\author{
${ }^{1}$ Department of Pathology, University of Sulaimani College of Medicine and Shoresh Teaching Hospital, Sulaimani, Iraq. \\ Department of Nephrology, University of Dohuk College of Medicine, Dohuk, Iraq. \\ *Correspondence to: Alaa Abbas Ali (E-mail: dr.alaaabbas@yahoo.com) \\ (Submitted: 11 November 2020 - Revised version received: 25 November 2020 - Accepted: 17 December 2020 - Published online: 26 February 2021)
}

\begin{abstract}
Objective Gene expression profiling by microarrays or RT PCR has been studied in certain western centers to enhance the diagnostic accuracy of allograft biopsy, however, such sophisticated tests are difficult to apply in developing countries. This study was conducted to evaluate the expression of von Willebrand factor (VWF) and Interferon-gamma (IFNY) as an end PCR product in renal allograft biopsy with different pathological categories.

Methods Forty-nine (49) indicated renal allograft biopsies were analyzed histologically by the Banff 2017 classification, inflammatory cell infiltration was analyzed by immunohistochemistry study for CD4, CD8, CD16, and CD68 markers, and a fresh tissue used for molecular study.

Results The biopsy findings were acute T-cell mediated rejection (A-TCMR) 30.6\%, interstitial fibrosis and tubular atrophy 22.4\%, C4dTransplant glomerulopathy $12.2 \%$, calcineurin inhibitor toxicity $10.2 \%$, C4d+antibody mediated rejection $10.2 \%$ and normal histology 14.3\%. The only significant difference in VWF expression was between acute TCMR and normal, P=0.01, Spearman's correlation also showed a significant relationship between VWF and acute TCMR ( $r=0.53, P=0.01)$, and VWF was found to correlate with the numbers of interstitial CD4+ $(r=0.29, P=0.03)$ and $C D 68+(r=0.37, P=0.007)$ cells. IFNy expression was significant in acute TCMR versus normal, $P=0.009$. Spearman's pair-wise testing showed that INFy correlated with CD8 in both the glomerular $(r=0.38, P=0.006)$ and interstitial $(r=0.30, P=0.04)$ compartments and with CD16+ interstitial cells $(r=0.36, P=0.01)$.

Conclusions Molecular and immunohistochemistry data of this study distinguish acute TCMR from other forms of transplant pathology and mildly dysfunctional kidneys with normal histology.

Keywords Renal allograft biopsy; VWF; IFNY; PCR; Kidney transplantation
\end{abstract}

\section{Introduction}

Kidney transplantation is the treatment of choice for patients with end-stage renal disease (ESRD), but because of the limited availability of dialysis in developing countries, it is the only option for the long-term survival of the great majority of the world's ESRD patient. ${ }^{1-3}$ Over the past decades, studies repeatedly documented kidney biopsy as the gold-standard for the diagnosis of allograft dysfunction. ${ }^{4}$ Kidney allograft biopsy diagnoses are primarily based upon histological findings and immunofluorescence staining for $\mathrm{C} 4 \mathrm{~d}$, and treatment is directed toward the pathologist diagnosis. ${ }^{5}$ But this histological assessment is restricted by the subjective interpretation of the lesions, making the histopathological diagnosis of limited reproducibility. ${ }^{6}$

Since 2009, many groups have investigated gene expression profiling by microarray or PCR in an attempt to improve the diagnostic accuracy of biopsy sample analysis. Sis et al. ${ }^{7}$ and Reeve et al. ${ }^{8}$ reported that biopsies with rejection (acute and chronic) showed three molecular profiles: Endothelial transcript, Natural killer (NK) cell-associated transcript, and IFN- $\gamma$.

The collaboration of Edmonton study group with European countries led to the INTERCOMEX Study, in which they used microarrays and algorithms to measure mRNA levels in 519 transplant biopsies from 10 North America and European centers, to assess T cells- and antibody-mediated rejection, the diagnoses assigned based on Molecular Microscopic Diagnostic System (MMDx). This study was able to differentiate rejection from non-rejection injury as kidney injury or inflammatory glomerular disease. ${ }^{9}$
Despite that molecular studies have contributed to our understanding of the mechanisms of renal graft pathology, the logistical issues and high cost of these sophisticated technics make it not practical to be used in daily diagnostic practice and management of graft recipients, especially in a developing country like Iraq. ${ }^{4}$

This study aims to evaluate whether reasonably inexpensive testing methods, as immunohistochemistry (IHC) and molecular expression of von Willebrand factor (VWF) and Interferon (IFN), might help discriminate acute rejection from other transplant disorder.

\section{Material and methods}

\section{Patients and sample collection}

This study included a total of 49 for-cause biopsies obtained between January 1, 2019 and December 31, 2019. A satisfactory biopsy was defined as having at least five glomeruli and one arterial cross-section. The biopsies were performed for poor function, deterioration in function, or proteinuria. Basic demographic and clinical parameters were retrieved from medical records.

\section{Histopathology and diagnostic criteria}

All biopsies were processed in the Histopathology Laboratory of Shorsh Hospital/Sulaymaniyah Governorate and studied by light microscopy in 18 serial sections using hematoxylin and eosin, periodic acid-Shiff, Masson trichrome stains. Jones periodic acid-methenamine silver stains were performed on 
selected cases to better see basement membrane changes. None of the biopsies were studied by electron microscopy. Direct immunofluorescence was performed on frozen sections using fluorescein-conjugated anti-human IgG, $\operatorname{IgM}, \operatorname{IgA}, \mathrm{C} 3$, C1q (DAKO, Santa Clara, CA). C4d staining was performed using a monoclonal anti-C4d antibody (Bio-Rad, Inc) by indirect immunofluorescence.

The histological findings were categorized based on the Banff 2017 Classification ${ }^{5,10}$ into normal or no specific changes, acute TCMR, C4d+ AMR, C4d-TG, IF/TA-NOS, and CNI toxicity. Transplant glomerulopathy (TG) is diagnosed by the presence of double contours of the glomerular basement membrane (GBM) graded at cglb and above after excluding other causes of double contour GBM such as thrombotic microangiopathy and glomerulonephritis. ${ }^{10}$

\section{Immunohistochemistry}

Positively charged slides were used for IHC staining with the following markers CD4 (Clone: RBT; CD4, Bio BS, USA), CD8 (Clone: EP334, Bio SB, USA), CD16 (Clone; EP364, Bio SB, USA), and CD68 (Dako, Glostrup, Denmark). These markers represent the cells involved in the major non-antibody pathways of innate and adaptive immunity.

\section{IHC stain scoring}

In all of the biopsies, we used IHC stain to assess the number of CD4+ cells, CD8+ cells, CD16+ cells, and CD68+ cells in two tissue compartments: intraglomerular and interstitium. The counting was performed manually at $400 \mathrm{x}$. Staining for CD4, CD8, CD16, and CD68 was quantified by averaging the number of cells stained in five glomeruli or five 400X microscopic fields of the interstitial areas.

\section{Molecular study}

RNA extraction. Messenger RNA was extracted from RNA later preserved kidney allograft specimens using Total RNA Purification Kit (NORGEN BIOTEK, ON, Canada) according to the manufacturer's instructions. The RNA was eluted in DEPC-treated water and stored at $-80^{\circ} \mathrm{C}$. RNA quality and concentration was assessed using Biophotometer (Eppendorf, Hamburg, Germany) at wavelengths 260/280.

Complementary DNA (cDNA) was constructed by GoScript Reverse Transcriptase PCR (Promega, Madison, WI, USA) according to the manufacturer's procedure.

Primer design and polymerase chain reaction. The primers sequences used in this study were taken from online articles (Bonthron et al. ${ }^{11}$ and Kim et al. ${ }^{12}$ ). The primers were purchased from GENEWIZ (NJ, USA). We used conventional polymerase chain reaction (PCR) (Applied BiosystemsVeriti 96-Well Thermal Cycler, USA), to detect the expression of VWF nucleotide sequences were as follows: sense primer: 5' AGGGACAGCTCCTGGATGA 3', anti-sense primer 5' ACTGGCAGATCCCACTGAAG 3', interferon-gamma (IFN- $\gamma$ ) nucleotide sequences were as follows: sense primer: 5' TGAATGTCCACCCGAAAGCA 3', anti-sense primer 5' CGACCTCGAAACAGCATCTGA 3', Human $\beta$-actin was employed as a housekeeping gene verify the integrity of target gene mRNA with nucleotide sequences were as follows: sense primer: 5' CACCAACTGGGACGACAT 3', anti-sense primer 5'ACAGCCTGGATAGCAACG 3'.11,12

The reaction mix and thermal cycling. $25 \mu \mathrm{l}$ Go Taq G2 Green Master Mix2X (Promega corp., Madison, WI, USA) reaction volume was prepared by adding the following: $2.5 \mu \mathrm{l}$ for each forward and reversed primer, $12.5 \mu \mathrm{l} \mathrm{Go} \mathrm{Tag} \mathrm{G2} \mathrm{Green} \mathrm{Mix,}$ $5.5 \mu \mathrm{l}$ nuclease-free water, and $2.0 \mu \mathrm{l}$ DNA template (c DNA). The mixture was placed in a PCR tube, then centrifuged for $10 \mathrm{sec}$, and placed into Applied Biosystem thermal cycler. The PCR reaction was performed as follows: Initial denaturation at $95^{\circ} \mathrm{C}$ of $2 \mathrm{~min}$ for $1 \mathrm{cycle}$, Denaturation at $95^{\circ} \mathrm{C}$ for $30 \mathrm{sec}$. for 35 cycles, annealing at $55^{\circ} \mathrm{C}$ for $1 \mathrm{~min}$. for 35 cycles and extension at $72^{\circ} \mathrm{C}$ for $1 \mathrm{~min}$. The resulting PCR products were analyzed by $2 \%$ agarose gel electrophoresis stained with ethidium bromide. The gel was run at 100 volts for $45 \mathrm{~min}$, and the cDNA fragments were visualized by UV-light as shown in Fig. 1.

\section{Statistical procedures}

The data were analyzed with IBM SPSS (Statistical Package for Social Science-version 26.0) C4d, VWF, IFN- $\gamma$ expression was recorded as binary positive or negative variables ( 0 or 1 ) and Banff scores as ordinal variables (scores $0,1,2,3$ ). The number of inflammatory cells in the glomerular or interstitial compartments were expressed as mean \pm SD. The continuous variables of age, time post-transplant (in days), and serum creatinine were not normally distributed and were expressed as the median and interquartile range (IQR). For IHC and molecular marker expression, each marker was analyzed by one-way analysis of variance (ANOVA) with post-hoc Tukey's test to determine differences between diagnostic groups. Paired comparisons between two diagnostic groups used Mann-Whitney $U$-tests. Spearman correlation was used to evaluate the paired relationships between molecular and IHC findings and diagnoses. Differences in categorical variables between-groups were evaluated by Chi-square or Fisher exact tests. Differences between two groups were considered significant at $\mathrm{P}<0.05$.

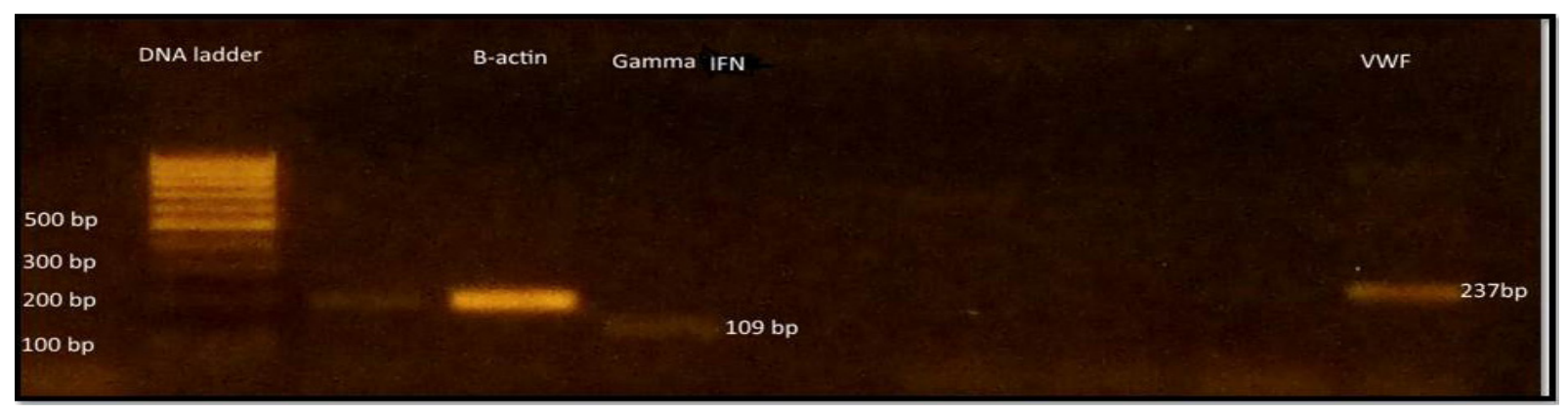

Fig. 1 PCR bands of VWF and IFN $y$ on gel electrophoresis.

Abbreviation: VWF, von Willebrand factor; IFN Interferon, B-actin, Beta actin. 


\section{Results}

\section{Patient characteristics}

The study included 49 kidney transplant recipients' patients who underwent a kidney biopsy. The transplant units do not perform protocol biopsies and all biopsies were for clinical indications. Median patient age was 37 years with an IQR of 24-48 years old. Recipients were $77.8 \%$ male. Median serum creatinine (S.Cr) was $2.0 \mathrm{mg} / \mathrm{dl}$ with an IQR of $1.7-2.8 \mathrm{mg} / \mathrm{dl}$. All 54 patients were found to have a median time of 365 days (IQR 29.5-1095). The patient characteristics are summarized in Table 1.

Abbreviations: Continuous variables of age and serum creatinine and time of biopsy are expressed as median and interquartile range. IQR, interquartile range, MMF: mycophenolate mofetil.

\section{Histopathological results}

The histological diagnosis and number of specimens consisted of acute TCMR, $\mathrm{n}=15$; C4d positive antibody-mediated rejection, $\mathrm{n}=5$ (including two cases of mixed acute T-CMR and acute C4d+AMR); CNI toxicity, $\mathrm{n}=5$; C4d-transplant glomerulopathy $n=6$; interstitial fibrosis and tubular atrophy, $n=11$ and normal histology, $\mathrm{n}=7$. The normal histology was associated with mild dysfunction post-transplantation and would represent mild AKI without identifiable pathological findings and serve as a non-rejection control.

\section{IHC evaluation of CD4, CD8, CD16, and CD68 positive cells}

The expression of different cellular markers in five major histological categories is shown in Table 2 with significant $P$ value in relation to normal histology. As shown in Table 2, CD16+ $(\mathrm{P}=0.02)$ expression in the glomerular compartment was higher in $\mathrm{C} 4 \mathrm{~d}+\mathrm{AMR}$ (Fig. 2), while CD68 ( $\mathrm{P}=0.04$ ) was significantly expressed in the C4d-TG group (Fig. 3).

\begin{tabular}{lc}
\hline \multicolumn{2}{l}{ Table 1. Clinical characteristic of recipients, $\mathbf{n}(\%)$} \\
\hline Data & Number (\%) \\
\hline Total number of recipients & $49(100)$ \\
Median age of recipients (yr) & 36 (IQR: $24-47)$ \\
Gender(Male) & $37(75.5)$ \\
Living/Deceased donor & $49 / 0(100)$ \\
Related/Unrelated donor & $6 / 43(12.2 / 87.8)$ \\
Median serum creatinine at biopsy (mg/dl) & $2($ IQR:1.7-2.8) \\
Previous transplant & $4(8.2)$ \\
Mediate time of biopsy (days) & $365($ IQR:43-1095) \\
Maintenance immunosuppressive regimens & \\
at biopsy & $34(69.4)$ \\
MMF, tacrolimus, steroid & $15(30.6)$ \\
MMF, cyclosporine, steroid & \\
Indication for biopsy: & $5(10.2)$ \\
Primary non function & $18(36.7)$ \\
Rapid deterioration of graft function & $20(40.8)$ \\
Slow deterioration of graft function & $2(4.1)$ \\
Proteinurea & $4(8.1)$ \\
Follow up biopsy & \\
\hline
\end{tabular}

Abbreviations: Continuous variables of age and serum creatinine and time of biopsy are expressed as median and interquartile range. IQR, interquartile range, MMF: mycophenolate mofetil.

\begin{tabular}{|c|c|c|c|c|c|c|c|}
\hline IHC & Compartment & Normal $(n=7)$ & A-TCMR $(n=15)$ & $C 4 d+A M R(n=5)$ & C4d-TG $(n=6)$ & IFTA $(n=11)$ & CNI Toxicity $(n=5)$ \\
\hline \multirow{2}{*}{ CD4 } & Glomerular & $\begin{array}{c}0.2 \pm 0.3 \\
1.000\end{array}$ & $\begin{array}{l}1.1 \pm 2.8 \\
0.808\end{array}$ & $\begin{array}{c}0.2 \pm 0.3 \\
1.000\end{array}$ & $\begin{array}{l}0.5 \pm 0.7 \\
0.945\end{array}$ & $\begin{array}{c}0.0 \pm 0.0 \\
0.737\end{array}$ & $\begin{array}{c}0.2 \pm 3.1 \\
1.000\end{array}$ \\
\hline & Interstitial & $\begin{array}{c}6.3 \pm 3.1 \\
1.000\end{array}$ & $\begin{array}{c}22.6 \pm 11.7 \\
\mathbf{0 . 0 0 1}\end{array}$ & $\begin{array}{c}24.7 \pm 19.9 \\
0.447\end{array}$ & $\begin{array}{c}16.2 \pm 13.4 \\
0.556\end{array}$ & $\begin{array}{c}11.2 \pm 6.4 \\
0.321\end{array}$ & $\begin{array}{c}15.9 \pm 10.8 \\
0.490\end{array}$ \\
\hline \multirow{2}{*}{ CD8 } & Glomerular & $\begin{array}{c}0.2 \pm 0.3 \\
1.000\end{array}$ & $\begin{array}{c}2.1 \pm 3.1 \\
0.229\end{array}$ & $\begin{array}{c}0.1 \pm 0.2 \\
1.000\end{array}$ & $\begin{array}{c}1.5 \pm 1.8 \\
0.556\end{array}$ & $\begin{array}{c}0.7 \pm 1.1 \\
0.698\end{array}$ & $\begin{array}{c}0.8 \pm 0.6 \\
0.400\end{array}$ \\
\hline & Interstitial & $\begin{array}{l}6.3 \pm 5 \\
1.000\end{array}$ & $\begin{array}{c}24.7 \pm 16.7 \\
\mathbf{0 . 0 1 2}\end{array}$ & $\begin{array}{l}21.4 \pm 7 \\
\mathbf{0 . 0 3 7}\end{array}$ & $\begin{array}{c}17.2 \pm 10.2 \\
0.279\end{array}$ & $\begin{array}{c}16 \pm 10 \\
0.144\end{array}$ & $\begin{array}{c}20.9 \pm 9.0 \\
0.115\end{array}$ \\
\hline \multirow{2}{*}{ CD16 } & Glomerular & $\begin{array}{c}0.7 \pm 0.8 \\
1.000\end{array}$ & $\begin{array}{c}4.7 \pm 4.7 \\
0.060\end{array}$ & $\begin{array}{l}4.1 \pm 1.4 \\
\mathbf{0 . 0 2 3}\end{array}$ & $\begin{array}{c}4.9 \pm 4.9 \\
0.433\end{array}$ & $\begin{array}{c}0.8 \pm 1.8 \\
1.000\end{array}$ & $\begin{array}{c}2.3 \pm 1.0 \\
0.181\end{array}$ \\
\hline & Interstitial & $\begin{array}{c}7.1 \pm 7.5 \\
1.000\end{array}$ & $\begin{array}{c}19.6 \pm 11.1 \\
0.062\end{array}$ & $\begin{array}{c}18.2 \pm 11.8 \\
0.501\end{array}$ & $\begin{array}{l}8.9 \pm 3.6 \\
0.845\end{array}$ & $\begin{array}{c}11 \pm 4.7 \\
0.818\end{array}$ & $\begin{array}{c}14.3 \pm 9.6 \\
0.736\end{array}$ \\
\hline \multirow{2}{*}{ CD68 } & Glomerular & $\begin{array}{c}1.5 \pm 1.6 \\
1.000\end{array}$ & $\begin{array}{c}2.9 \pm 4.1 \\
0.917\end{array}$ & $\begin{array}{c}5.4 \pm 1.7 \\
0.430\end{array}$ & $\begin{array}{c}7.6 \pm 7.2 \\
P=0.044\end{array}$ & $\begin{array}{c}1.1 \pm 1.4 \\
0.994\end{array}$ & $\begin{array}{c}1.2 \pm 1.1 \\
0.999\end{array}$ \\
\hline & Interstitial & $\begin{array}{c}7 \pm 5 \\
1.000\end{array}$ & $\begin{array}{c}19.8 \pm 8.6 \\
0.004\end{array}$ & $\begin{array}{c}24 \pm 11.0 \\
0.084\end{array}$ & $\begin{array}{c}19.1 \pm 10.1 \\
0.204\end{array}$ & $\begin{array}{c}12.2 \pm 4.6 \\
0.317\end{array}$ & $\begin{array}{c}12.6 \pm 6.0 \\
0.880\end{array}$ \\
\hline
\end{tabular}

NOTE: In each cell upper numbers are mean \pm standard deviation and lower numbers are $P$ values. Significant differences are bolded with the reference having a P value of 1.000

Abbreviation: A-TCMR; Acute T cell-mediated rejection, AMR; antibody mediated rejection; TG, transplant glomerulopathy; IFTA; interstitial fibrosis and tubular atrophy; $\mathrm{CNl}$; calcineurin inhibitor toxicity. 

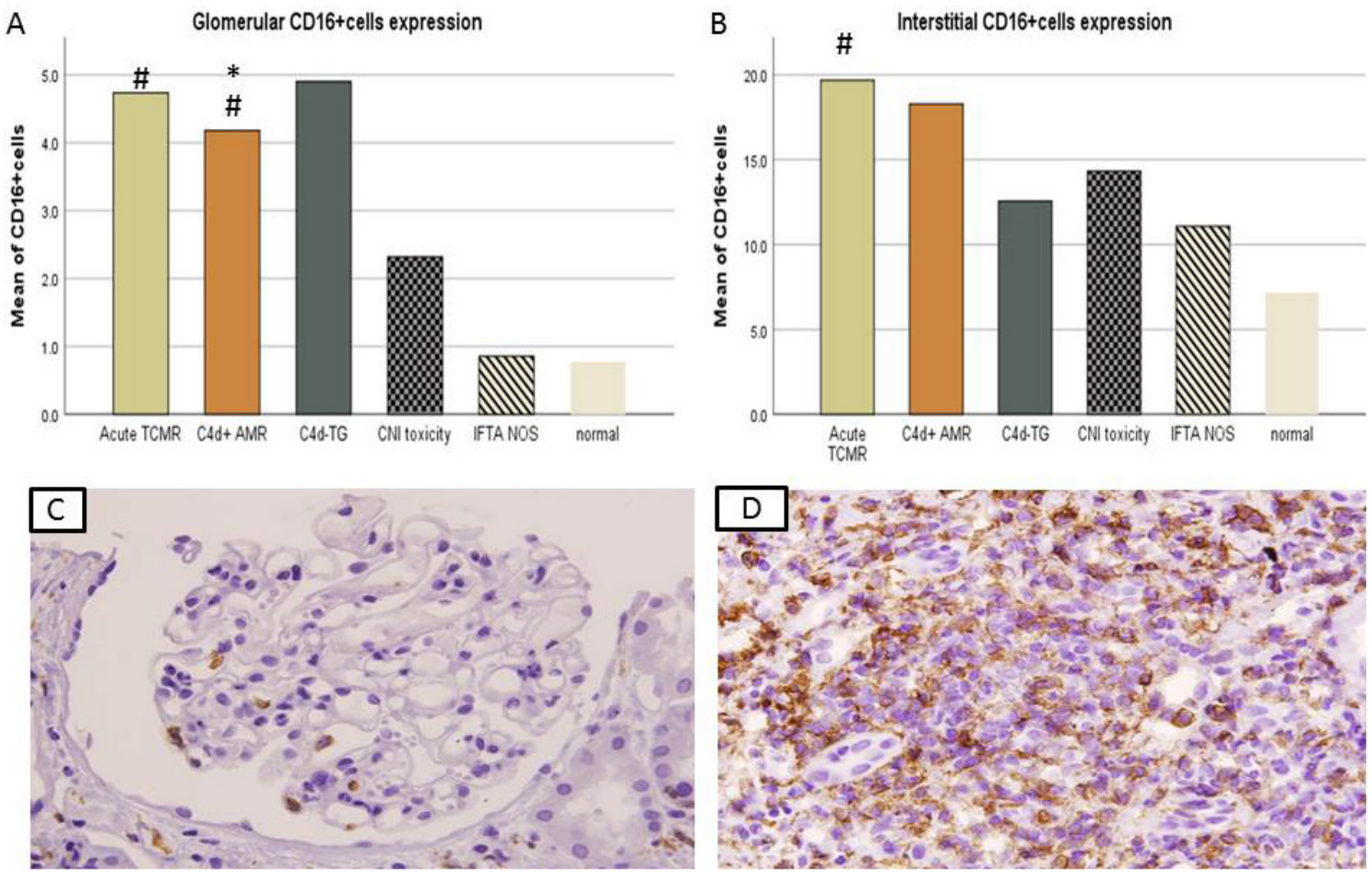

Fig. 2 Compartment-specific CD16+cell expression. A and C, Glomerular. B and D, Interstitial in renal allograft biopsies in different diagnostic categories. \# $\mathbf{p}<\mathbf{0 . 0 5}$ vs. normal histology. ${ }^{*} \mathrm{p}<0.05$ vs. IFTA.

A
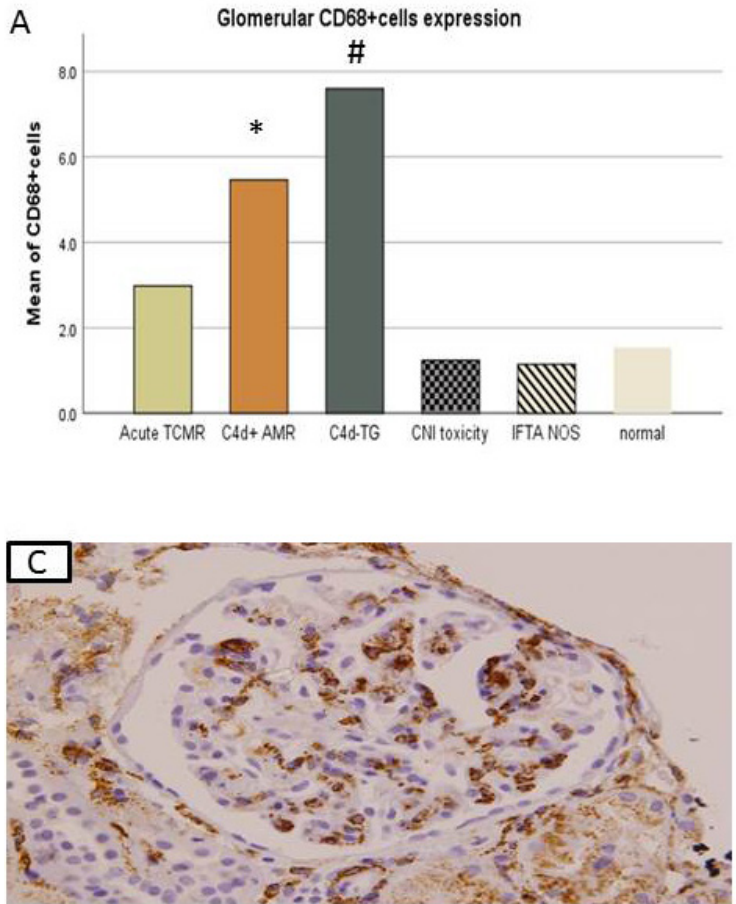
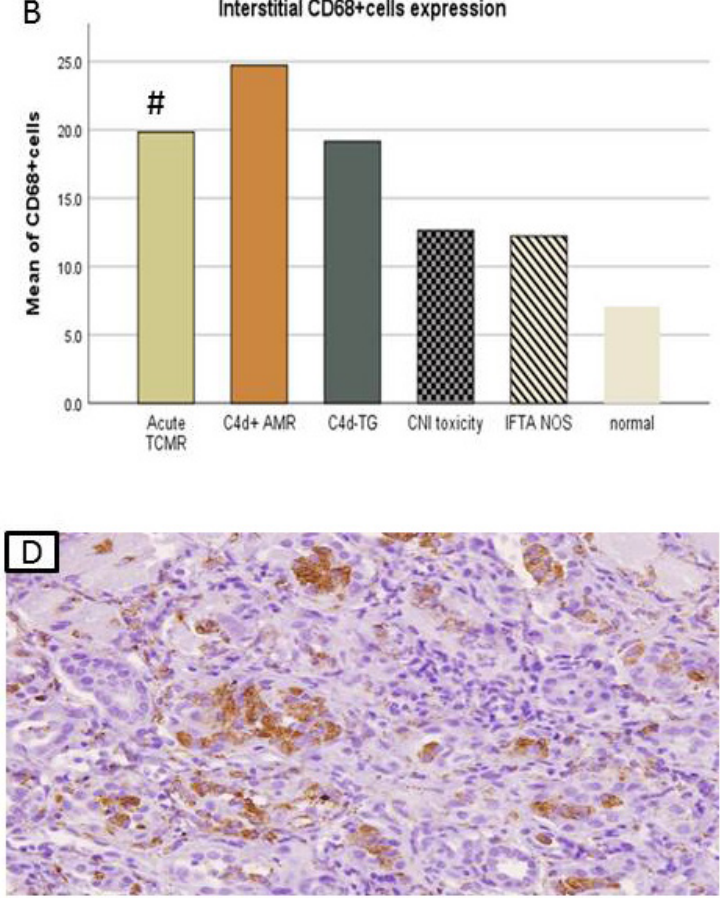

Fig. 3 Compartment-specific CD68+cell expression. A and C, Glomerular. B and D, Interstitial in renal allograft biopsies in different diagnostic categories. \# $\mathbf{p}<\mathbf{0 . 0 5}$ vs. normal histology.*

${ }^{*} \mathrm{p}<0.05$ vs. IFTA. 
CD4+, CD8+, and CD68+ cells staining were pronounced in the interstitial compartment of acute TCMR.

\section{Molecular result of von Willebrand factor (VWF) and Interferon-gamma (IFNY) expression in different diagnostic groups}

Molecular result for VWF. VWF was found in $20 \%$ of acute TCMR, $8 \%$ of IF/TA, $6 \%$ of C4d-AMR, $2 \%$ of CNI toxicity, $2 \%$ of TIN, $2 \%$ of AKI, and $2 \%$ of normal biopsies. When these proportions were compared using a Fisher exact test, the only significant difference in VWF expression was between acute TCMR and normal, $\mathrm{P}=0.01$. Fig. 4 . Spearman's correlation also showed a significant relationship between VWF and acute TCMR ( $\mathrm{r}=0.53, \mathrm{P}=0.01$ ), and VWF was found to correlate with the numbers of interstitial CD4+ $(\mathrm{r}=0.29, \mathrm{P}=0.03)$ and CD68+ $(\mathrm{r}=0.37, \mathrm{P}=0.007)$ cells (Table 3$)$.

Molecular results for IFN $\gamma$. IFN $\gamma$ was expressed in acute TCMR (16\%), IF/TA (8\%), C4d-AMR (2\%), TIN (2\%), ATN (4\%), and CNI toxicity (4\%). There was no expression of IFN $\gamma$ in C4d-AMR nor normal histology.

A Fisher exact test was used to compare the expression of IFN $\gamma$ in different diagnostic groups and found that the only significant difference was between acute TCMR and normal, $\mathrm{P}=0.01$ Fig. 5 . Spearman's pair-wise testing showed that INF $\gamma$ correlated with CD8 in both the glomerular $(\mathrm{r}=0.38, \mathrm{P}=0.006)$ and interstitial $(\mathrm{r}=0.30, \mathrm{P}=0.04)$ compartments and with $\mathrm{CD} 16+$ interstitial cells $(\mathrm{r}=0.36, \mathrm{P}=0.01)$ (Table 3$)$.

\section{Discussion}

In this study, we applied molecular testing and IHC to a subset of 2019 biopsies was to evaluate whether reasonably inexpensive testing methods might help discriminate between acute and the several chronic transplant disorders, and whether this might have any application in an under-resourced medical transplant setting. We selected primers for two cDNA transcripts: 1. VWF was used as endothelial activation markers. 2. IFN $\gamma$ was used as a general inflammatory marker. ${ }^{13,14}$

Our results showed intra-glomerular CD16+cells predominate in C4d+AMR while CD68+cells were increased in the glomerular compartment of C4d- TG as compared to normal histology and to IF/TA ( $\mathrm{P}=0.04 \& 0.01)$.

Glomerular CD68+cells correlate with C4d- TG, and C4d+AMR, while CD16+cells correlate with C4d+AMR only. These findings are similar to studies performed by others using IHC study dos Santos et al. ${ }^{15}$ and Divella et al. ${ }^{16}$ or by using macrophages associated transcript Hayde et al. ${ }^{17}$ and Lefaucheur et al. ${ }^{18}$

We obtained good results for VWF and IFN $\gamma, \mathrm{VWF}$ and IFN $\gamma$ are the end-products of activation cascades and are expressed constitutively at fairly high levels in an inflammatory reaction. In expression arrays, the great majority of the markers are stimulatory molecules that upregulate the expression of constitutive end-products, but these molecules are often transiently expressed at much lower levels than the end-products and can be difficult to detect without the proper systems. ${ }^{13}$

We were able to demonstrate that IFN $\gamma$ levels were significantly associated with increased numbers of tissue infiltrating CD8+ T cells and CD16+ cells. The results also showed that an increased expression of VWF was significantly associated with interstitial infiltrates of CD68+ macrophages, which agrees with Batal et al ${ }^{19}$ study, which stated that VWF expression by IHC associated with peritubular capillaritis. The numbers of tissue infiltrating CD4+ T cells, CD8+ T cells, CD16+ cells, and CD68+ macrophages were significantly associated with each other, and with the diagnosis of acute TCMR, these findings were similar to dos Santos et al. study. ${ }^{15}$ This produced a high degree of discrimination between acute TCMR and kidneys with mild dysfunction and normal histology (i.e. nonrejection). These inflammatory markers were just as elevated in C4d+ ABMR as they were for acute TCMR, but the small number of biopsies in the C4d+ ABMR group did not allow

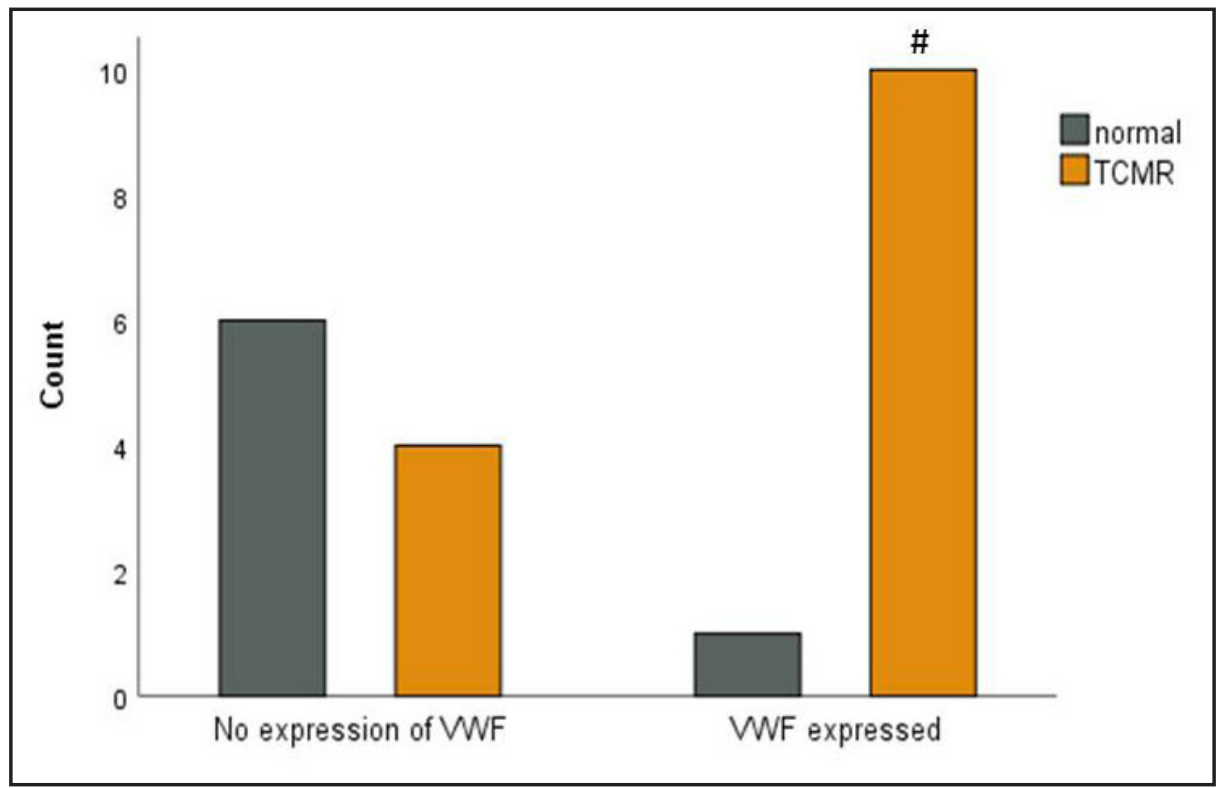

Fig. 4 VWF expression in renal allograft biopsies showing acute T cell-mediated rejection (TCMR) versus normal histology. $\# p<0.05$. 


\begin{tabular}{|c|c|c|c|c|c|c|c|}
\hline Compartments & & aTCMR & C4d-TG & C4d+AMR & IF/TA & VWF & IFN- $\gamma$ \\
\hline Glomerular & Statistic & & & & & & \\
\hline \multirow{2}{*}{ CD4 } & $r^{*}$ & 0.25 & 0.15 & 0.05 & -0.44 & 0.10 & 0.13 \\
\hline & $p$ & ns & ns & ns & $0.06 \mathrm{~ns}$ & ns & ns \\
\hline \multirow{2}{*}{ CD8 } & $r^{*}$ & 0.49 & 0.41 & -0.27 & 0.15 & 0.05 & 0.38 \\
\hline & $p$ & 0.02 & ns & ns & ns & ns & 0.006 \\
\hline \multirow{2}{*}{ CD16 } & $r^{*}$ & 0.37 & 0.45 & 0.86 & -0.20 & 0.06 & 0.13 \\
\hline & $p$ & ns & ns & $<0.001$ & ns & ns & ns \\
\hline \multirow{2}{*}{ CD68 } & $r^{*}$ & 0.08 & 0.60 & 0.81 & -0.12 & 0.15 & 0.17 \\
\hline & p & ns & 0.03 & 0.001 & ns & Ns & ns \\
\hline \multicolumn{8}{|l|}{ Interstitial } \\
\hline \multirow{2}{*}{ CD4 } & $r^{*}$ & 0.68 & 0.53 & 0.61 & 0.38 & 0.29 & 0.18 \\
\hline & $p$ & 0.0004 & $0.05 \mathrm{~ns}$ & 0.03 & ns & 0.03 & ns \\
\hline \multirow{2}{*}{ CD8 } & $r^{*}$ & 0.63 & 0.57 & 0.80 & 0.58 & 0.05 & 0.30 \\
\hline & $p$ & 0.002 & 0.03 & 0.001 & 0.01 & ns & 0.04 \\
\hline \multirow{2}{*}{ CD16 } & $r^{*}$ & 0.59 & 0.41 & 0.61 & 0.42 & 0.27 & 0.36 \\
\hline & $p$ & 0.004 & ns & 0.03 & ns & ns & 0.01 \\
\hline \multirow{2}{*}{ CD68 } & $r^{*}$ & 0.66 & 0.71 & 0.85 & 0.50 & 0.37 & 0.22 \\
\hline & $p$ & 0.001 & 0.008 & 0.001 & 0.03 & 0.007 & ns \\
\hline \multicolumn{8}{|l|}{ Molecular } \\
\hline \multirow{2}{*}{ VWF } & $r^{*}$ & 0.53 & 0.47 & 0.35 & 0.26 & & \\
\hline & $p$ & 0.01 & ns & ns & ns & & \\
\hline \multirow{2}{*}{ IFN- $\gamma$} & $r^{*}$ & 0.55 & 0.35 & not detected & 0.46 & & \\
\hline & $p$ & 0.009 & ns & ns & ns & & \\
\hline
\end{tabular}

Abbreviation: a TCMR, acute T-cell mediated rejection; AMR, antibody mediated rejection; TG; transplant glomerulopathy; IF/TA, interstitial fibrosis and tubular atrophy; Ns, not significant; $r *$, Spearman's correlation coefficient. $P<0.05$ was bolded.

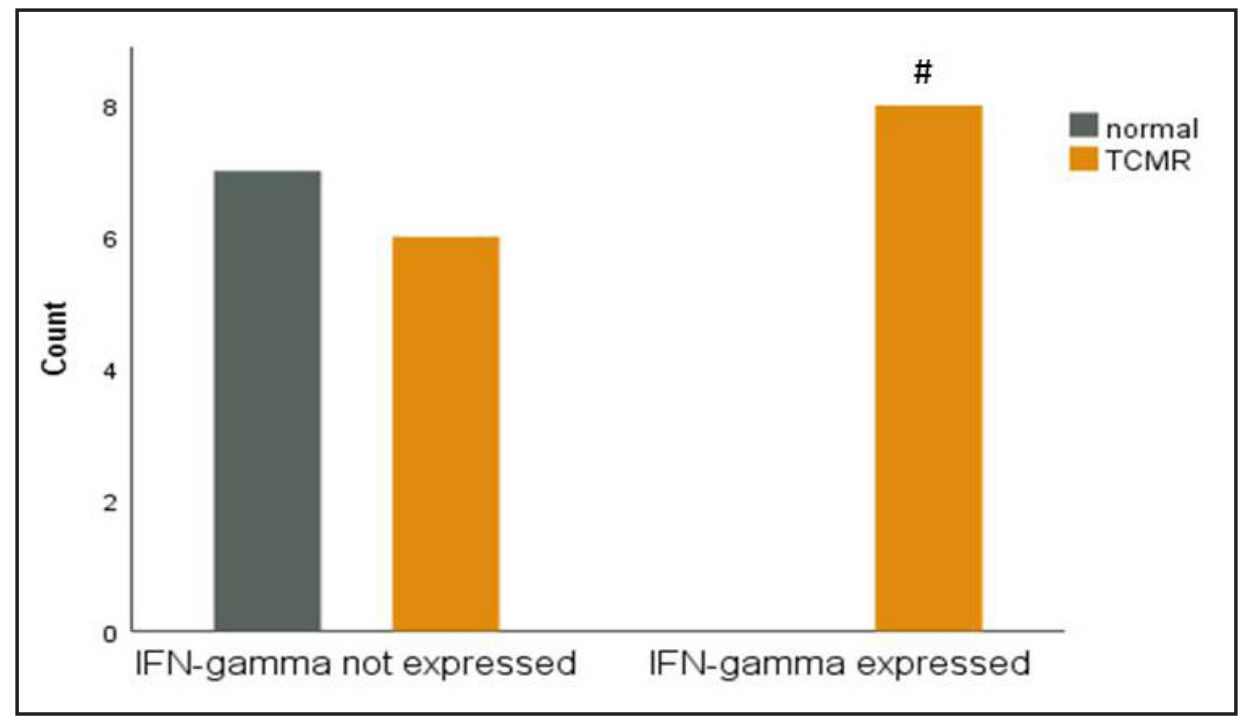

Fig. 5 IFN- $\gamma$ expression in acute T cell-mediated rejection (TCMR) versus normal histology. $\# p<0.05$. 
for the differences between most markers to reach significance. Similarly, the values of the markers were generally low to intermediate for TG and IF/TA suggesting that our testing tended to identify these disorders as inflammatory poor processes, which they are by routine light microscopy.

In summary, our molecular and IHC data distinguish acute TCMR from other forms of transplant pathology and mildly dysfunctional kidneys with normal histology. This is an indication that some form of basic molecular testing could be designed for our transplant services. If a true quantitative system could be developed and appropriate controls established, this might be of clinical importance for distinguishing between post-transplant dysfunction, borderline rejection, and acute TCMR. Among our patients, these categories comprise over $50 \%$ of our biopsies. Such testing has been performed in the United States by whole-genome expression profiling on peripheral blood samples, with the results being as discriminative between acute TCMR, normal histology, and acute dysfunction with non-rejection as the results reported from the INTERCOMEX trials. ${ }^{19}$

\section{Conclusion}

Based on our findings, we can suggest that CD16 and CD68 markers can express themselves in different compartments depending on the underlying pathology. Our result also showed that some form of basic molecular testing could be designed for our transplant services to differentiate acute TCMR from other forms of transplant pathology and mildly dysfunctional kidneys.

\section{Declarations}

\section{Acknowledgments}

The authors would like to acknowledge the Kurdistan Institution for strategic studies and scientific research, the University of Sulaimani, and Histopathological laboratory of Shorsh hospital for their facilities, services, and support.

\section{Competing interests}

None to declare.

\section{Ethical Approval}

This study was approved by the ethical committee of the faculty of medical sciences /University of Sulaimani in the Kurdistan Region, Iraq under protocol number (\#11N/29). It carried out on indicated graft biopsies and it involved no additional patient intervention that did not require informed consent.

\section{References}

1. JHA V, CHUGH K. Dialysis in developing countries: Priorities and obstacles. Nephrology. 1996;2(2):65-71

2. Zhou J, D’Agati V, Laszik Z, Nadasdy T. Silva's diagnostic renal pathology. Cambridge: Cambridge University; 2016.

3. Parajuli S, Aziz F, Garg N, Panzer S, Joachim E, Muth B et al. Histopathological characteristics and causes of kidney graft failure in the current era of immunosuppression. World J Transplant. 2019;9(6):123-1

4. Williams W, Taheri D, Tolkoff-Rubin N, Colvin R. Clinical role of the renal transplant biopsy. Nat Rev Nephrol. 2012;8(2):110-121.

5. Haas M, Loupy A, Lefaucheur C, Roufosse C, Glotz D, Seron D et al. The Banff 2017 Kidney Meeting Report: Revised diagnostic criteria for chronic active T cell-mediated rejection, antibody-mediated rejection, and prospects for integrative endpoints for next-generation clinical trials. Am J Transplant. 2018;18(2):293-3

6. Mengel M, Sis B, Halloran P. SWOT Analysis of Banff: strengths, weaknesses, opportunities and threats of the International Banff Consensus process and classification system for renal allograft pathology. Am J Transplant. 2007;7(10):2221-2226.

7. Sis B, Jhangri G, Bunnag S, Allanach K, Kaplan B, Halloran P. Endothelial gene expression in kidney transplants with alloantibody indicates antibody-mediated damage despite lack of C4d staining. Am J Transplant. 2009;9(10):2312-2323.

8. Reeve J, Einecke G, Mengel M, Sis B, Kayser N, Kaplan B et al. Diagnosing rejection in renal transplants: a comparison of molecular-and histopathology-based approaches. Am J Transplant. 2009;9(8):1802-1810.

9. Halloran P, Reeve J, Akalin E, Aubert O, Bohmig G, Brennan D et al. Real time central assessment of kidney transplant indication biopsies by microarrays: the INTERCOMEX study. Am J Transplant. 2017;17(11):2851-2862.

10. Roufosse C, Simmonds N, Clahsen-van Groningen M, Haas M, Henriksen K, Horsfield C et al. A 2018 Reference guide to the Banff classification of renal allograft pathology. Transplantation. 2018;102(11):1795-1814.

11. Bonthron D, Handin R, Kaufman R, Wasley L, Orr E, Mitsock L et al. Structure of pre-pro-von Willebrand factor and its expression in heterologous cells. Nature. 1986:324(6094):270-273.

12. Kim S, Kim YK, Lee H, Cho JE, Kim HY et al. Interferon gamma mRNA quantitative real-time polymerase chain reaction for the diagnosis of latent tuberculosis: a novel interferon gamma release assay. Diagn Microbiol Infect Dis. 2013, 75, 68-72

13. Halloran P. Venner J, Madill-Thomsen K, Einecke G, Parkes M, Hidalgo L et al. Review: The transcripts associated with organ allograft rejection. Am J Transplant. 2017;18(4):785-795.

14. Adam B, Afzali B, Dominy K, Chapman E, Gill R, Hidalgo L et al. Multiplexed color-coded probe-based gene expression assessment for clinical molecular diagnostics in formalin-fixed paraffin-embedded human renal allograft tissue. Clin Transplant. 2016;30(3):295-305

15. dos Santos D, Campos E, Saraiva Câmara N, David D, Malheiros D. Compartment-specific expression of natural killer cell markers in renal transplantation: immune profile in acute rejection. Transplant Int. 2015;29(4):443-452

16. Divella C, Rossini M, Loverre A, Schena A, Maiorano A, Gesualdo V et al. Immunohistochemical characterization of glomerular and tubulointerstitial infiltrates in renal transplant patients with chronic allograft dysfunction. Nephrol Dial Transplant. 2010;25(12):4071-4077.

17. Hayde N, Bao Y, Pullman J, Ye B, Calder R, Chung M et al. The clinical and genomic significance of donor-specific antibody-positive/C4dnegative and donor-specific antibody-negative/C4d-negative transplant glomerulopathy. Clin J Am Soc Nephrol. 2013:8(12):2141-2148.

18. Lefaucheur C, Viglietti D, Hidalgo L, Ratner L, Bagnasco S, Batal I et al. Complement-activating anti-HLA antibodies in kidney transplantation: allograft gene expression profiling and response to treatment. J Am Soc Nephrol. 2017;29(2):620-635

19. Batal I, Azzi J, El-Haddad N, Riella L, Lunz J, Zeevi A et al. Immunohistochemical markers of tissue injury in biopsies with transplant glomerulitis. Human Pathol. 2012:43(1):69-80.

20. Kurian S, Williams A, Gelbart T, Campbell D, Mondala T, Head S et al. Molecular classifiers for acute kidney transplant rejection in periphera blood by whole genome gene expression profiling. Am J Transplant. 2014;14(5):1164-1172. 